Address for correspondence: Andrew M. Ramey, US Geological Survey Alaska Science Center, 4210 University Dr, Anchorage, AK 99508, USA; email: aramey@usgs.gov

\section{New Reassortant Clade 2.3.4.4b Avian Influenza A(H5N6) Virus in Wild Birds, South Korea, 2017-18}

\author{
Jung-Hoon Kwon, ${ }^{1}$ Sol Jeong, ${ }^{1}$ Dong-Hun Lee, \\ David E. Swayne, Yu-jin Kim, Sun-hak Lee, \\ Jin-Yong Noh, Tseren-Ochir Erdene-Ochir, \\ Jei-Hyun Jeong, Chang-Seon Song
}

Author affiliations: Konkuk University, Seoul, South Korea

(J.-H. Kwon, S. Jeong, Y.-J. Kim, S.-H. Lee, J.-Y. Noh,

T.-O. Erdene-Ochir, J.-H. Jeong, C.-S. Song); US Department of Agriculture, Athens, Georgia, USA (D.-H. Lee, D.E. Swayne)

DOI: https://doi.org/10.3201/eid2410.180461

We isolated new reassortant avian influenza $A(H 5 N 6)$ viruses from feces of wild waterfowl in South Korea during 2017-18. Phylogenetic analysis suggested that reassortment occurred between clade 2.3.4.4b H5N8 and Eurasian low pathogenicity avian influenza viruses circulating in wild birds. Dissemination to South Korea during the 2017 fall migratory season followed.

$\mathrm{C}$ lade 2.3.4.4 H5 highly pathogenic avian influenza viruses (HPAIVs) have evolved by reassortment with different neuraminidase (NA) and internal genes of prevailing low pathogenicity avian influenza viruses (LPAIVs) and other HPAIVs to generate new genotypes and further evolved into genetic subgroups A-D since 2014 (1). Among these, subgroups A and B viruses were disseminated over vast geographic regions by migratory wild birds (2,3). Subgroup B influenza A(H5N8) viruses were detected in Qinghai Lake, China, and Uvs-Nuur Lake, Russia, during May-June 2016 (Qinghai/Uvs-like), followed by the identification of reassortant viruses in multiple Eurasian countries (4-6). Recently, subgroup B H5N6 viruses were isolated from birds in Greece during February 2017 and England, Germany, the Netherlands, Japan, and Taiwan during winter 2017-18 $(7,8)$.

${ }^{1}$ These authors contributed equally to this article.
During December 2017-January 2018 in South Korea, we isolated 6 H5N6 HPAIVs from 231 fecal samples of wild birds collected from the banks of the Cheongmi-cheon River $\left(37^{\circ} 06^{\prime} 56.9^{\prime \prime} \mathrm{N}, 127^{\circ} 25^{\prime} 18.3^{\prime \prime} \mathrm{E}\right)$ and 34 from $222 \mathrm{fe}-$ cal samples collected from the banks of the Gokgyo-cheon River $\left(36^{\circ} 45^{\prime} 12.3^{\prime} \mathrm{N}, 127^{\circ} 07^{\prime} 12.7^{\prime} \mathrm{E}\right.$ ) (online Technical Appendix 1, https://wwwnc.cdc.gov/EID/article/24/10/180461-Techapp1.pdf). These wild bird habitats are wintering sites of migratory waterfowl, including mallard (Anas platyrhynchos), spot-billed duck (Anas poecilorhyncha), Mandarin duck (Aix galericulata), and common teal (Anas crecca). The Gokgyo-cheon River is a major habitat site for Mandarin ducks, and numerous HPAIVs were detected in fecal samples from Mandarin ducks during 2011, 2015, and 2016 (9). We identified avian influenza virus-positive fecal samples from 38 Mandarin ducks and 2 mallards, based on DNA barcoding technique (10). We performed full-length genome sequencing and comparative phylogenetic analysis on 19 of the 40 isolates (online Technical Appendix 1; online Technical Appendix 2, https://wwwnc.cdc.gov/EID/ article/24/10/18-0461-Techapp2.xlsx).

All H5N6 isolates shared high nucleotide sequence identities in all 8 gene segments $(99.58 \%-100 \%)$ and were identified as HPAIVs based on the presence of multiple basic amino acids at the HA proteolytic cleavage site (PLREKRRKR/G). Searches of the GISAID (https:// www.gisaid.org) and BLAST (https://blast.ncbi.nlm.nih. gov/Blast.cgi) databases indicated that all 8 genomes had the highest nucleotide identity with A/Great_Blackbacked_Gull/Netherlands/1/2017 (Netherlands/1) clade 2.3.4.4 subgroup B H5N6 strain from December 2017 (99.17\%-99.79\%), rather than subgroup B H5N6 viruses from Japan and Taiwan collected during December 2017 $(97.18 \%-99.27 \%)$.

In phylogenetic analysis, we identified 2 genotypes of subgroup B H5N6 viruses (online Technical Appendix 1 Figures 1, 2): genotypes B.N6.1 and B.N6.2. The genotype B.N6.1 viruses were identified from South Korea, Japan, Taiwan, Greece, and the Netherlands (Netherlands/1 strain), and the genotype B.N6.2 viruses were detected from England, Germany, and the Netherlands. For genotype B.N6.1, all genes except NA clustered with H5N8 HPAIV of previously reported genotypes, H5N8-NL cluster I in the Netherlands (6), Ger-11-16 in Germany (5), and Duck/Poland/82a/16-like in Italy (4). The NA gene clustered with LPAIVs circulating in wild birds in Eurasia and separated into 2 clusters, suggesting the potential for $>2$ independent reassortment events between $\mathrm{H} 5 \mathrm{~N} 8$ virus and unidentified wild bird origin N6 segments. Consistent clustering of South Korea isolates with the Netherlands/1 strain in maximum-likelihood (ML) phylogenies for each gene supported by high ML bootstrap values (86-100) suggests their close relationship. The genotype B.N6.2 viruses 
Table. Time to most recent common ancestor for each gene segment of genotype B.N6.1 influenza A(H5N6) viruses isolated in South Korea, December 2017-January 2018*

\begin{tabular}{|c|c|c|c|c|c|c|}
\hline \multirow[b]{2}{*}{ Gene } & \multicolumn{2}{|c|}{ South Korea isolates, node 1} & \multicolumn{2}{|c|}{$\begin{array}{l}\text { South Korea and Europe isolates, } \\
\text { node } 2\end{array}$} & \multicolumn{2}{|c|}{$\begin{array}{c}\text { South Korea, Europe, Japan, Taiwan, and } \\
\text { Greece isolates, node } 3\end{array}$} \\
\hline & Mean & $95 \%$ HPD & Mean & $95 \%$ HPD & Mean & $95 \%$ HPD \\
\hline PB2 & 2017 Sep & 2017 Jul-Oct & 2017 May & 2016 Dec-2017 Sep & 2016 Mar & 2015 Oct-2016 Jun \\
\hline PB1 & 2017 Sep & 2017 Jul-Oct & 2017 May & 2017 Feb-Aug & 2016 Jul & 2016 May-Aug \\
\hline PA & 2017 Sep & 2017 Aug-Oct & 2017 Jul & 2017 Apr-Sep & 2016 Oct & 2016 Jul-Dec \\
\hline $\mathrm{HA}$ & 2017 Sep & 2017 Jul-Oct & 2017 May & 2017 Feb-Jul & 2016 Mar & 2015 Dec-2016 May \\
\hline NP & 2017 Jul & 2017 Apr-Sep & 2017 Mar & 2016 Nov-2017 Jun & 2016 Jan & 2015 Jul-2016 May \\
\hline NA & 2017 Jul & 2017 Mar-Sep & 2017 Feb & $2016 \mathrm{Jul}-2017 \mathrm{Jul}$ & 2015 Sep & 2014 Aug-2016 Aug \\
\hline$M$ & 2017 Aug & 2017 May-Oct & 2017 May & 2017 Jan-Aug & $2016 \mathrm{Mar}$ & 2016 Jan-May \\
\hline NS & $2017 \mathrm{Jul}$ & 2017 Apr-Oct & 2017 Mar & 2016 Nov-2017 Jun & 2016 Feb & 2015 Oct-2016 Jun \\
\hline
\end{tabular}

had different polymerase basic 2 (PB2) and polymerase acidic (PA) genes from genotype B.N6.1. The polymerase basic 2 gene probably originated from other LPAIVs, and a polymerase acidic gene originated from H5N8-NL cluster II genotype $(6,7)$. The phylogenetic network and ML analysis suggest that H5N6 viruses have evolved from subgroup $\mathrm{B}$ H5N8 viruses into 3 independent pathways, detected in Greece, Europe/South Korea, and Japan/Taiwan (online Technical Appendix 1, Figures 2,3).

The time of most recent common ancestry (tMRCA) for each gene of genotype B.N6.1 H5N6 viruses isolated during winter 2017-18 in Eurasia, except for the NA gene, ranged from January 2016 to October 2016, suggesting that genotype B.N6.1 viruses diverged during the previous year. The tMRCA of the NA gene was September 2015 (95\% highest posterior density August 2014-August 2016). The tMRCA of the NA gene has wide $95 \%$ highest posterior density range because only a few recent N6 genes of LPAIVs were available in databases for analysis. The tMRCA for each gene of H5N6 HPAIVs identified in South Korea ranged from July through September 2017, suggesting that ancestors of these viruses emerged among wild birds during or after summer 2017, possibly at the breeding and molting sites in the Palearctic region (Table; online Technical Appendix Figure 4). Detection of H5N6 HPAIV from fecal samples of wild birds in South Korea during the 2017-18 wintering season and our phylogenetic analysis suggest that the viruses had moved through wild birds during the fall migration season.

On the basis of our data and migratory pattern of birds, we estimate that H5N6 viruses possibly descended from H5N8 viruses circulating during 2016-17, reaching breeding regions of wild birds during early 2017, followed by dissemination into Europe and East Asia during the fall migration. Enhanced surveillance in wild birds is needed for early detection of new introductions of HPAIV and to trace the transmission route of HPAIV.

This work was funded by Konkuk University in 2015.

\section{About the Author}

Mr. Kwon is a PhD candidate at Konkuk University, Seoul, South Korea. His primary research interest is the epidemiology of HPAIVs in wild birds. Ms. Jeong is a PhD candidate at Konkuk University, Seoul. Her primary research interest is the epidemiology of viruses in wild birds.

\section{References}

1. Sonnberg S, Webby RJ, Webster RG. Natural history of highly pathogenic avian influenza H5N1. Virus Res. 2013;178:63-77. http://dx.doi.org/10.1016/j.virusres.2013.05.009

2. Lee DH, Bertran K, Kwon JH, Swayne DE. Evolution, global spread, and pathogenicity of highly pathogenic avian influenza H5Nx clade 2.3.4.4. J Vet Sci. 2017;18(S1):269-80. http://dx.doi.org/10.4142/jvs.2017.18.S1.269

3. Global Consortium for H5N8 and Related Influenza Viruses. Role for migratory wild birds in the global spread of avian influenza H5N8. Science. 2016;354:213-7. http://dx.doi.org/10.1126/ science.aaf 8852

4. Fusaro A, Monne I, Mulatti P, Zecchin B, Bonfanti L, Ormelli S, et al. Genetic diversity of highly pathogenic avian influenza $\mathrm{A}(\mathrm{H} 5 \mathrm{~N} 8 / \mathrm{H} 5 \mathrm{~N} 5)$ viruses in Italy, 2016-17. Emerg Infect Dis. 2017;23:1543-7. http://dx.doi.org/10.3201/eid2309.170539

5. Pohlmann A, Starick E, Grund C, Höper D, Strebelow G, Globig A, et al. Swarm incursions of reassortants of highly pathogenic avian influenza virus strains H5N8 and H5N5, clade 2.3.4.4b, Germany, winter 2016/17. Sci Rep. 2018;8:15. http://dx.doi.org/10.1038/ s41598-017-16936-8

6. Beerens N, Heutink R, Bergervoet SA, Harders F, Bossers A, Koch G. Multiple reassorted viruses as cause of highly pathogenic avian influenza A(H5N8) virus epidemic, the Netherlands, 2016. Emerg Infect Dis. 2017;23:1974-81. http://dx.doi.org/10.3201/ eid2312.171062

7. Beerens N, Koch G, Heutink R, Harders F, Vries DPE, Ho C, et al. Novel highly pathogenic avian influenza A(H5N6) virus in the Netherlands, December 2017. Emerg Infect Dis. 2018; 24:770-3. http://dx.doi.org/10.3201/eid2404.172124

8. Liu YP, Lee DH, Chen LH, Lin YJ, Li WC, Hu SC, et al. Detection of reassortant H5N6 clade 2.3.4.4 highly pathogenic avian influenza virus in a black-faced spoonbill (Platalea minor) found dead, Taiwan, 2017. Infect Genet Evol. 2018;62:275-8. http://dx.doi.org/10.1016/j.meegid.2018.04.026

9. Kwon JH, Lee DH, Swayne DE, Noh JY, Yuk SS, Erdene-Ochir TO, et al. Reassortant clade 2.3.4.4 avian influenza $\mathrm{A}(\mathrm{H} 5 \mathrm{~N} 6)$ virus in a wild Mandarin duck, South Korea, 2016. Emerg Infect Dis. 2017;23:822-6. http://dx.doi.org/10.3201/ eid2305.161905 
10. Lee DH, Lee HJ, Lee YJ, Kang HM, Jeong OM, Kim MC, et al. DNA barcoding techniques for avian influenza virus surveillance in migratory bird habitats. J Wildl Dis. 2010;46:649-54. http://dx.doi.org/10.7589/0090-3558-46.2.649

Address for correspondence: Chang-Seon Song, Avian Disease Laboratory, College of Veterinary Medicine, Konkuk University, 1 Hwayang-dong, Gwangjin-gu, Seoul, 143-701, South Korea; email: songcs@konkuk.ac.kr

\section{Clinical Isolation and Identification of Haematospirillum jordaniae}

\author{
Gregory Hovan, Andrew Hollinger \\ Author affiliations: Delaware Public Health Laboratory, \\ Smyrna, Delaware, USA (G. Hovan); Regional Hospital, \\ Delaware $^{1}$ (A. Hollinger)
}

DOI: https://doi.org/10.3201/eid2410.180548

A clinical case study involving a man (35-49 years of age) with wounds to his lower right extremity. An isolate was sent to the Delaware Public Health Laboratory for confirmatory testing by genetic analysis of the $16 \mathrm{~S}$ gene. Testing identified the isolate as a novel genus and species, Haematospirillum jordaniae.

$\mathrm{T}$ he Centers for Disease Control and Prevention (CDC) recently recognized a human pathogen, Haematospirillum jordaniae, as a new bacterial genus and species (1). $H$. jordaniae is a gram-negative, spiral-shaped aerobe in the family Rhodospirillaceae (1). Before the pathogen's identification, this organism was isolated 14 times from 10 different states. These organisms were received by CDC's Special Bacteriology Reference Laboratory, Division of High-Consequence Pathogens and Pathology, National Center for Emerging and Zoonotic Infectious Diseases, over the course of 10 years (February 2003-October 2012) before the initial publication. Here we report the clinical identification of $H$. jordaniae, a potential emerging infectious pathogen, by the Delaware Public Health Laboratory (DPHL) and describe possible routes of infection.

${ }^{1}$ Location redacted for patient confidentiality.
A man (35-49 years of age) sought care at a hospital emergency department in September 2016 with worsening pain, redness, and swelling of the right lower extremity, which had an open wound on the right shin. The patient stated that he had finished a project cutting stones 3 weeks earlier where the water and stone chips were hitting his right leg. The patient ignored swelling, erythema, and fever he experienced around the same period when the stonecutting occurred and decided not to seek medical intervention until he was no longer able to ignore the symptoms.

The patient was found to have cellulitis of the right leg and sepsis, and he was admitted to the hospital for treatment. On the same day, he was started on intravenous clindamycin, and blood cultures were collected. The infectious disease physician discontinued clindamycin and placed the patient on vancomycin, ciprofloxacin, and aztreonam because of concern for potential infection with Pseudomonas, Aeromonas, or methicillin-resistant Staphylococcus aureus. Growth was observed in both sets of aerobic bottles, the first after 2 days, 15 hours, and the second after 4 days, 18 hours. Blood cultures grew gram-negative bacilli, leading the infectious disease physician to remove vancomycin but continue with ciprofloxacin and aztreonam. The patient improved before identification of the pathogen and was discharged on oral ciprofloxacin.

Gram stain of the organism revealed small, curved, gram-negative bacilli, resembling Campylobacter. Subcultures from the bottles did not grow aerobically until 48 hours after incubation on sheep's blood agar and chocolate agar. The organisms did not grow on MacConkey agar or when incubated anaerobically on blood agar. Although it was suspected that the organism might be a Campylobacter species, it did not grow in a microaerophilic environment. Biochemical testing revealed the organism as oxidase-positive, indole-negative, catalase-positive, and urease-negative (using urea agar). The isolate was sent to the DPHL for identification.

DPHL received a grown isolate from the submitting hospital 8 days after the patient's admission. The organism was cultured in the same manner as described previously; phenotypic tests were consistent with the findings of the submitting hospital. Initial identification was performed at DPHL, but the pathogen could not be determined because the organism was not part of the instrument's stored database.

The isolate's DNA was extracted and amplified by using general methods described in numerous publications. The sample generated an 845-bp portion of the $16 \mathrm{~S}$ region. The assembled sequence was uploaded to opensource rRNA databases for comparison, including GenBank BLAST (https://blast.ncbi.nlm.nih.gov/Blast.cgi), the Ribosomal Database Project (https://rdp.cme.msu. edu/), and MicrobeNet (https://microbenet.cdc.gov). Samples most closely matched to Novispirillum itersonii strain 